\title{
The Architecture Studio of Universiti Kebangsaan Malaysia (UKM): Has the Indoor Environmental Quality Standard Been Achieved?
}

\author{
A. I. Che-Ani ${ }^{1,2}$, N. M. Tawil ${ }^{1,2}$, A. R. Musa ${ }^{1}$, H. Yahaya ${ }^{3}$ \& M. M. Tahir ${ }^{1}$ \\ ${ }^{1}$ Department of Architecture, Faculty of Engineering and Built Environment, Universiti Kebangsaan Malaysia, \\ Selangor, Malaysia \\ ${ }^{2}$ Centre for Engineering Education Research, Faculty of Engineering and Built Environment, Universiti \\ Kebangsaan Malaysia, Selangor, Malaysia \\ ${ }^{3}$ Faculty of Architecture and Built Environment, Twintech International University College of Technology, \\ Kuala Lumpur, Malaysia \\ Correspondence: A. I. Che-Ani, Department of Architecture, Faculty of Engineering and Built Environment, \\ Universiti Kebangsaan Malaysia, 43600 UKM Bangi, Selangor, Malaysia. Tel: 60-3-8921-6985. E-mail: \\ adiirfan@gmail.com
}

\author{
Received: October 5, 2012 Accepted: November 23, 2012 Online Published: November 30, 2012 \\ doi:10.5539/ass.v8n16p174 \\ URL: http://dx.doi.org/10.5539/ass.v8n16p174
}

\begin{abstract}
Studio-based learning is a shared learning environment in which ambiguous problems are addressed. This paper primarily focused on the lightings at the Universiti Kebangsaan Malaysia (UKM)'s architecture studio and to find out whether it had achieved the Indoor Environmental Quality (IEQ). A good design, involving a space in a building, requires sufficient daylight in order to perform a task. This can be achieved by providing enough means to let in diffused light from the sky, yet keeping out direct light from the sun to prevent heat gain and glare. The purpose of this research was to identify the importance of the IEQ in creating conducive studio-based learning environment. The IEQ is crucial for a learning institution since indoor environment factors can actually affect human comfort, health and productivity. Lighting is most important to students as high-quality lighting will improve students' moods, behavior, concentration, and consequently, their learning. However, the effectiveness of learning in a studio cannot be fully achieved if the IEQ is being overlooked. Presently, artificial lights are being used most of the time in the UKM architecture studios in order to optimize students' vision and comfort. Using an equipment, named LM-8100, and supported by a questionnaire survey to gauge the lighting comfort level from the students' perspective, a lighting reading was taken for a duration of 10-hours for three days in the UKM third year architecture studio. The finding showed that the lighting setting is not within the range of the Malaysian Code of Practice on Indoor Air Quality (IAQ). However, the students have perceived it as normal and thus, the situation does not hinder them to stay long inside their studio. This situation will affect the students' ability to perceive visual stimuli in the short-term and health, in terms of students' vision, in the long run.
\end{abstract}

Keywords: IEQ, architecture studio, UKM, lighting

\section{Introduction}

Indoor Environmental Quality (IEQ) is important to the health, comfort, and well-being of the occupants in a building. The effect of poor IEQ can create the Sick Building Syndrome (SBS) symptom. For instance, headaches and fatigue are very common as are dry or irritated eyes, skin irritation, sinus infections, or nasal congestion, nausea, respiratory irritation, and allergies. There are various aspects of the indoor environment that can affect the occupant's well-being and performance (Prakash, 2005). Although there has been no scientific proof made in relation to an occupant's performance and competence due to the indoor environmental quality, the quality of the indoor environment has, generally, affected the occupant's health. Work productivity may be interrupted as a result of bad health and bad physical condition (Kamaruzzaman \& Sabrani, 2011).

When discussing the IEQ, there are several factors influencing good indoor environment. Qualities as of thermal comfort, lighting, acoustical, as well as, air in a room are important factors influencing the IEQ (Bluyssen, 2009; Dascalaki, Gaglia, Balaras and Lagoudi, 2008; Mahbob et al., 2011). In this research, the IEQ of Universiti Kebangsaan Malaysia (UKM) Architecture Studio was analysed and the focus was on the lighting quality and 
thermal comfort.

\section{Lighting Quality}

Lighting plays a very important part in our life. Lighting is one of the parameters that influence IEQ. Before the 1940s, daylight was the primary light source in buildings; with artificial lights supplementing the natural light. In a short span of 20 years, electric lighting transformed a workplace by meeting most or all the occupants' lighting requirements (Edwards \& Torcellini, 2002). According to Dr. Ott (Ott Biolight Systems Inc., 1997), the body uses light as a nutrient for metabolic processes similar to water or food. On a cloudy day or under poor lighting conditions, the inability to perceive colours from the light can affect our mood and energy level. Liberman (1994) also mentioned that light plays a role in maintaining health. Obviously, students cannot study unless lighting is adequate, and there have been many studies reporting optimal lighting levels (Mayron, Ott, Nations \& Mayron, 1974). For architecture students, the studio is a place far more than just a normal classroom activity. Lighting plays an important role to these students as high-quality lighting can improve students' moods, behavior, concentration, and their learning, in general.

\section{Thermal Comfort}

Thermal comfort is one of the important aspects in achieving the IEQ and it should be given considerable attention by architects and designers. Indoor temperature affects several human responses, including thermal comfort, perceived air quality, SBS symptoms and performance at work (Seppänen, Fisk \& Lei, 2006).

Indoor environment, on the other hand, is important for learning as it affects indoor physical environment and, subsequently, students' health and quality of life (Fisk, 2000). An ideal thermal condition in the learning environment affects the mental efficiency of the students in situations where students perform clerical tasks calling for quick recognition and response (Peccolo, 1962). In relation to mental efficiency and thermal conditions, it was found that human beings work most efficiently at psychomotor tasks when the environment is at a comfortable temperature (Canter, 1976). Temperature is also implicated in studies of SBS. Maintaining a temperature at the low end of the comfort zone tends to reduce SBS symptoms. Similarly, individuals perceive the quality of indoor air to be better when temperature and/or humidity are towards the low end rather than the high end of the comfort zone (Fang, Clausen \& Fanger, 1998). There is also good evidence that moderate changes in room temperature, even within the comfort zone, affect children's abilities to perform mental tasks requiring concentration, such as addition, multiplication, and sentence comprehension (Wyon, 1999). For architecture students, studio-based learning is a place where most students spend time, not only for studying and doing their work, but also a place for having discussion and relaxing (Osman et al., 2009).

\section{Materials and Method}

In this study, two procedures were used to measure the IEQ of the UKM architecture studios. First, the lighting quality and second, thermal comfort. As for the research, two methods were used, i.e. measurement method and questionnaire survey. To determine the lighting quality, an equipment named LM-8100 (for physical measurement) and FLUKE Thermal Imager (for infra red image) were used to measure the lighting level. Lighting measurements were taken at three specific locations at L1, L2, and L3 at the UKM third year architecture studio as shown in Figure 1. Each reading was taken for a duration of 11-hours for two consecutive days. The studio chosen for this study was located in the south wing of the building with the floor area of 182 $\mathrm{m}^{2}$.

On the other hand, the temperature reading was recorded to measure the thermal comfort in the UKM third year architecture studio. The readings were taken at three different locations, i.e. the front, the middle and the back of the studio. Similar to the lighting measurement, each location had been labelled as L1, L2, and L3 as in Figure 1. The temperature reading was recorded every hour for 10 hours from 8.00 am until $6.00 \mathrm{pm}$ for two days by using an equipment named LM-8100 (for physical measurement) and FLUKE Thermal Imager (for infra red image).

The second method in this research involved a questionnaire survey to support the accuracy and effectiveness of data collection. According to Fraser, Anderson and Walberg (1982) and Rivera and Ganaden (2001), there are advantages of conducting research using the questionnaire method to obtain students' perceptions of learning environment as compared to observation. The main reason for using questionnaires is that it can be done directly and it is more economical as compared to the observation technique in the studio space. The use of students' perceptions involves a combination of views expressed by all the students who work in the studio, whilst the observation technique deals with the views from just one observer (Che Ahmad, Osman \& Halim, 2010).

The survey was conducted to all third year architecture students who occupy the studio. The questionnaires were designed to identify the existing scenario in the architecture studio that is related to the temperature comfort and 
humidity and also the importance of temperature comfort in students' perspective. This questionnaire also is important at gauging the lighting comfort levels from the students' perspective since lighting contributes to the principal needs such as performance, comfort and ambience for learning environment (Zainol, 2008). The results of all the three approaches i.e. the lighting measurement, the temperature measurement and questionnaire survey, were discussed and presented. The overview of the internal view of the UKM third year architecture studio is shown in figure 2 and exterior perspective of the third year architecture studio is shown in figure 3.

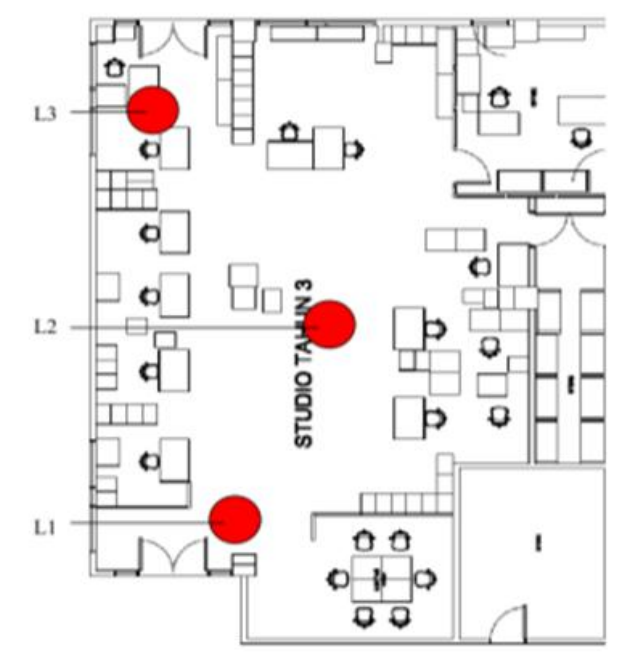

Figure 1. Location of data collection labeled L1, L2 and L3
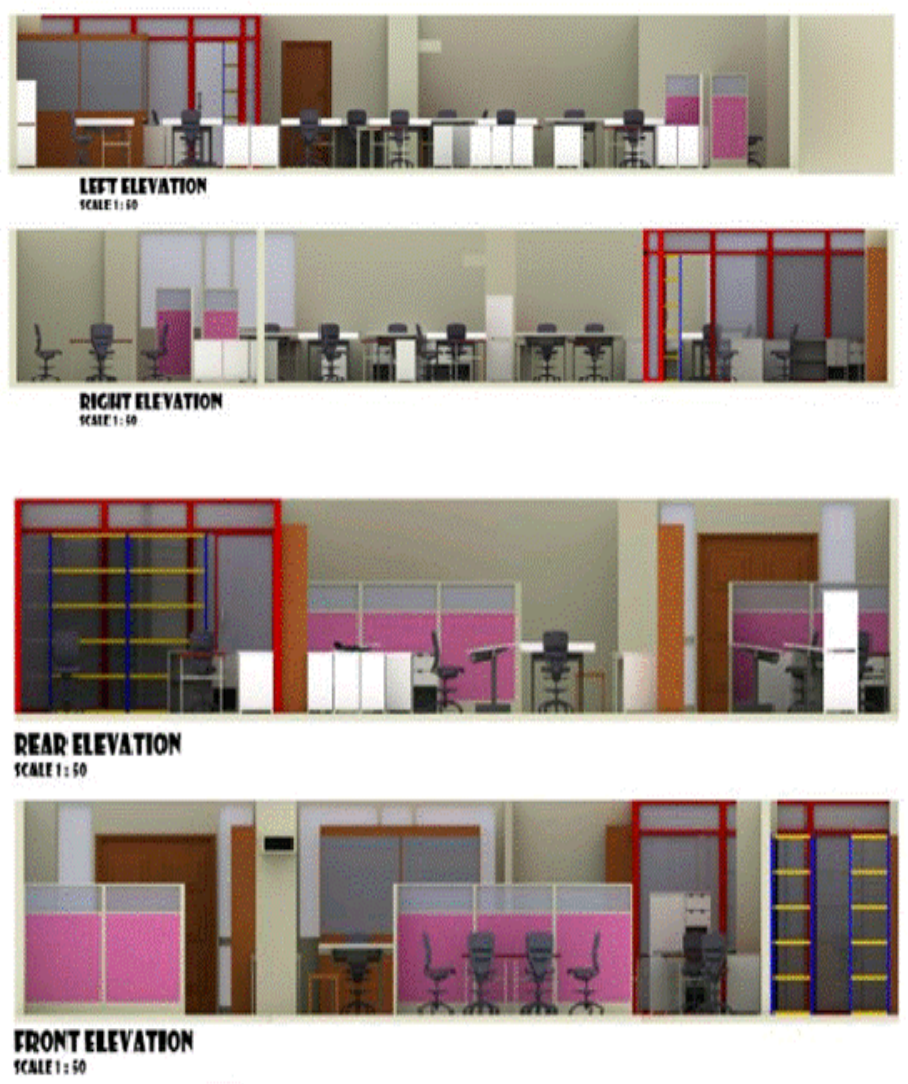

Figure 2. Elevation of the studio 


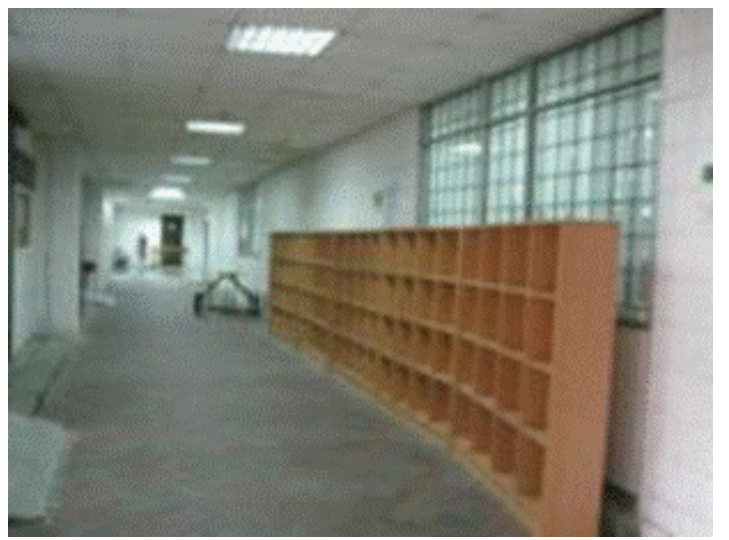

Figure 3. Exterior perspective of the UKM third year architecture studio

\section{Malaysian Standard}

\subsection{Lighting}

Based on Malaysian Standard (MS) 1525: 2007 "Code of Practice on Energy Efficiency and use of Renewable Energy for Non-Residential Building", indoor light requirements vary depending on the task to be carried out in working environments such as offices or schools. It is, generally, more effective to provide a low level background lighting that is between 150 - 200lux which is sufficient for orientation and general activities. However, it is different for a learning-based studio. The studio is a place for architecture students to do their work such as drafting, making a model and drawing. According to the MS 1525:2007, the lighting level recommended is 300-400lux. Typical lighting requirements for a variety of tasks are given in Table 1.

Table 1. Recommended average luminance levels

\begin{tabular}{ll}
\hline Task and examples of application & Illuminance [Lux] \\
\hline
\end{tabular}

\section{Lighting to infrequently used areas}

$\begin{array}{ll}\text { Minimum service illuminance } & 20\end{array}$

$\begin{array}{ll}\text { Interior walkway and car-park } & 50\end{array}$

$\begin{array}{ll}\text { Hotel bedroom } & 100\end{array}$

$\begin{array}{ll}\text { Lift interior } & 100\end{array}$

$\begin{array}{ll}\text { Corridor, passageways, stairs } & 100\end{array}$

Escalator, travelator $\quad 150$

$\begin{array}{ll}\text { Entrance and exit } & 100\end{array}$

$\begin{array}{ll}\text { Staff changing room, cloak room, lavatories, stores } & 100\end{array}$

$\begin{array}{ll}\text { Entrance hall, lobbies, waiting room } & 100\end{array}$

$\begin{array}{ll}\text { Inquiry desk } & 300\end{array}$

$\begin{array}{ll}\text { Gate house } & 200\end{array}$

Lighting for working interiors

$\begin{array}{ll}\text { Infrequent reading and writing } & 200\end{array}$

General offices, shops and stores, reading and writing $\quad 300-400$

$\begin{array}{ll}\text { Drawing office } & 300-400\end{array}$

$\begin{array}{ll}\text { Restroom } & 150\end{array}$

$\begin{array}{ll}\text { Restaurant, cafeteria } & 200\end{array}$

Kitchen $\quad 150-300$

Lounge $\quad 150$

$\begin{array}{ll}\text { Bathroom } & 150\end{array}$

$\begin{array}{ll}\text { Toilet } & 100\end{array}$ 
Bedroom

Classroom, library

Shop, supermarket, department store

Museum and gallery

\section{Localised lighting for exacting task}

Proof reading

Exacting drawing

Detailed and precise work
100

$300-500$

200-750

300

500

1000

2000

Source: Malaysian Standard MS 1525:2007

\subsection{Thermal Comfort}

Current comfort standards are intended to optimize the thermal acceptability of indoor environments. Therefore, in setting a good practice for IEQ, this study was based on the Malaysian Standard (MS) 1525: 2007 "Code of Practice on Energy Efficiency and the Use of Renewable Energy for Non-Residential Building” which are as follows:

Internal space environment:

1) Proposed design of the dry ball temperature (dry bulb): $23^{\circ} \mathrm{C}-26^{\circ} \mathrm{C}$

2) Minimum temperature of dry ball (dry bulb): $22^{\circ} \mathrm{C}$

3) Proposed Relative Humidity (RH): 5 5-70\%, and proposed air movement: $0.15-0.5 \mathrm{~m} / \mathrm{s}$

\section{Finding and Discussion}

\subsection{Lighting Analysis}

The findings in Figure 4 and 5 showed that the lighting measurement on L1, L2 and L3 varied on both days, i.e. day 1 and day 2 . The lighting data recorded at L1 for day 1 and day 2 showed the rates are very low as compared to the other locations of L2 and L3. From the L1 lighting analysis, it was found that the lighting measurement from 8 am to $6 \mathrm{pm}$ is in the range of 0 lux close to 100 lux. This means that this location (L1) is unsuitable for working or studying. However, this area is part of students' working area; despite it supposedly being the entrance area. While the L2 and L3 lighting readings for both locations are within 150lux to 250 lux. Unfortunately, this luminance is still not according to Malaysian Standard MS 1525:2007, where the appropriate luminance for drawing office (studio) is in the range 300-400 lux. The lighting results for L1, L2 and L3 for both days show the luminance in the UKM third year architecture studio is below the standard.

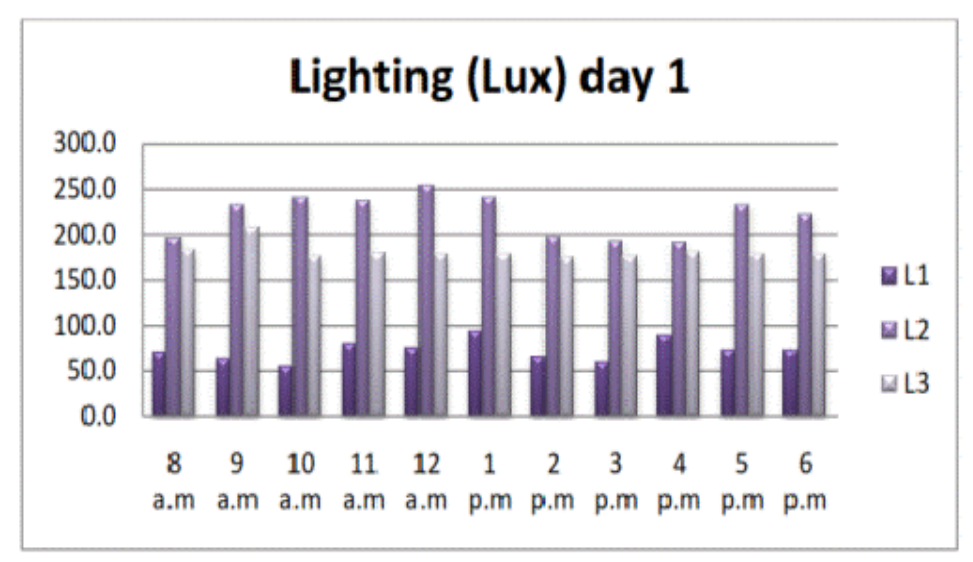

Figure 4. Lighting readings at year 3 studio on day 1 


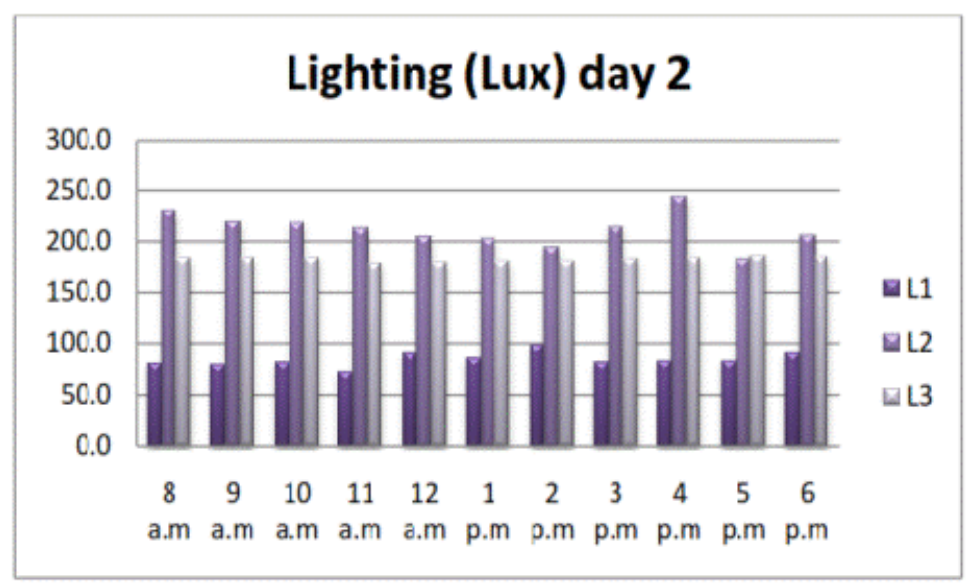

Figure 5. Lighting readings at year 3 studio on day 2

The results revealed some differences in lighting for day 2 of which the highest lighting's reading was recorded at 4 p.m. at L2, whereas on day 1 the highest lighting reading recorded was at 12 p.m. at the same location. The lowest result on day 1 was recorded at 11 a.m with the reading, approximately, at 70 lux. Unfortunately, on day 2, the lowest reading shown was, approximately, at 50 lux at 10 a.m.

The findings proved that lighting range in UKM third year architecture studio is not in accordance with the MS 1525:2007, of which the internal space environment should have a luminance in the range of 300-400 lux. This means that the indoor environment for UKM third year architecture studios does not comply with the suggested lighting settings at all three locations in the studio. Lighting is and has always been an important factor in designing and operating all learning environments because of its influence on the interacting parameters of the IEQ (Plymton, Conway \& Epstein, 2000; Benya, 2001).

\subsection{Temperature Analysis}

Figure 7 shows the temperature analysis of the indoor environment of the UKM third year architecture studio on day 1 . The indoor temperature showed the lowest reading recorded at 8 a.m. at L2, and the highest reading at 1 pm was also detected at L2 (in the middle of the studio). From day 1, the temperature analysis displayed the temperature reading in the range of $26.5^{\circ} \mathrm{C}$ to $28^{\circ} \mathrm{C}$ from 8 a.m. to 6 p.m..

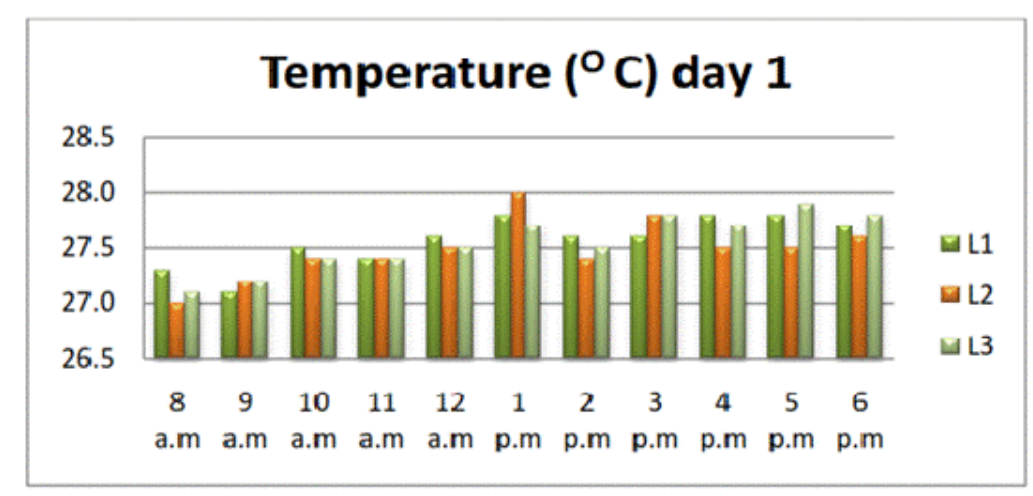

Figure 6. Temperature readings at year 3 studio on day 1

Figure 8 presents the temperature analysis of the indoor environment of the UKM third year architecture studio on day 2. The lowest temperature reading was at 9 a.m. revealed at L2 and 11 a.m. at L3 where the temperature reading was $27.9^{\circ} \mathrm{C}$, while the highest temperature was at $1 \mathrm{a} . \mathrm{m}$. captured at $\mathrm{L} 1$ with the temperature reading at $28.7^{\circ} \mathrm{C}$ and the range of temperature reading from $8 \mathrm{am}$ to $6 \mathrm{pm}$ was between $27.4^{\circ} \mathrm{C}$ to $28.7^{\circ} \mathrm{C}$. The temperature range on day 2 was higher than day 1 . 


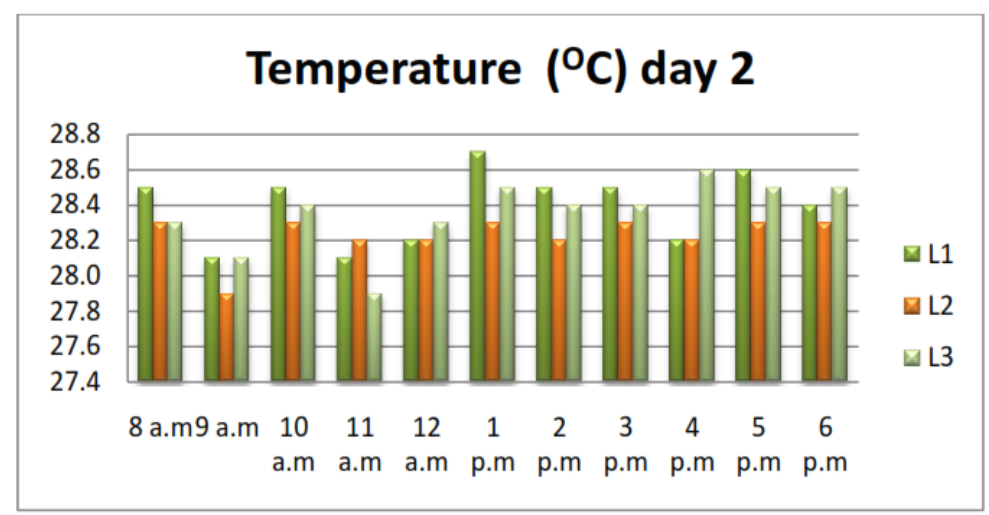

Figure 7. Temperature reading at year 3 studio on day 2

These findings show that the temperature range in the UKM third year architecture studio is not in accordance with the MS 1525:2007, of which the internal space environment should be using a dry bulb with temperature ranging from $23^{\circ} \mathrm{C}-26^{\circ} \mathrm{C}$. This means that the IEQ for the UKM third year architecture studio is not in accordance with the suggested temperature settings for all three locations in the studio. As for graphic image as shown in Figure 9, it was captured using FLUKE Thermal Imager.

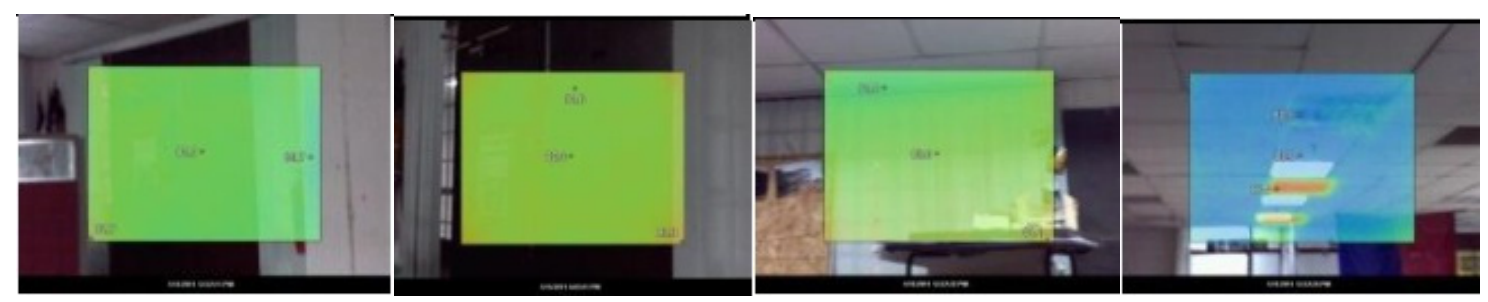

Figure 8 . Thermal image of year 3 studio

\subsection{Questionnaire Survey}

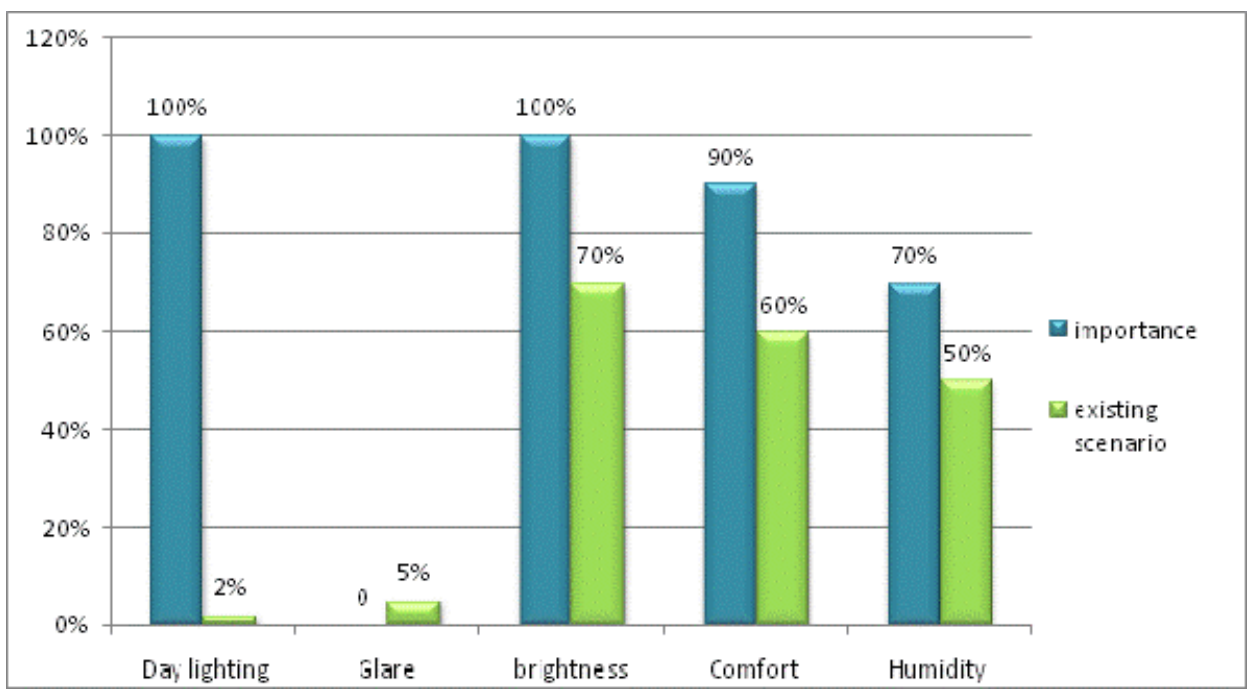

Figure 9. Questionnaires result, satisfaction scores for all year 3 architecture students

The questionnaire survey was carried out among all UKM third year architecture students who were occupying the studio. There were 12 respondents involved in the survey. The questionnaire included five parameters in order to identify the students' satisfaction on lighting and thermal comfort level. These students were among those occupying the studio most of the time. The five parameters indicated in the questionnaire consisted of day lighting, glare, brightness, comfort and humidity. The scores were calculated based on the students' responses on the importance of these five parameters and the existing scenario in the studio.

Figure 10 shows the finding of the questionnaire survey. Day lighting and brightness are perceived as important to the students. Nevertheless, it is sufficiently provided in the studio. The scores showed that the glare factor is 
not important at all (as the case should be) for them. However, in the existing scenario, the day lighting is not available. This scenario occurred because the studio is located far from sources of sunlight. Moreover, this space was not originally designed for architecture studio. This is the reason why the presence of natural lighting is almost $0 \%$ in this studio. On the contrary, the comfort and humidity were perceived as important by the students, with above $70 \%$ of importance level recorded. For the existing scenario, the students' satisfaction levels are acceptable with the score of $50 \%$ and above for both parameters.

\section{Matrix of the IEQ for UKM Architecture Studio}

The data for this research comprised both the measurements and a questionnaire survey. By combining these two sources of data, it was then simplified to define the matrix of the IEQ analysis for architecture studio. The matrix was presented in three categories, namely "Good", "Need Improvement" and "Poor", as shown in figure 11. The "Good" matrix was achieved when both parameters were in accordance with the MS 1525:2007 and the survey findings was above 50\% respectively; and vice versa for "Poor" matrix. For the "Need Improvement" matrix, either one of the parameters was either good or poor.

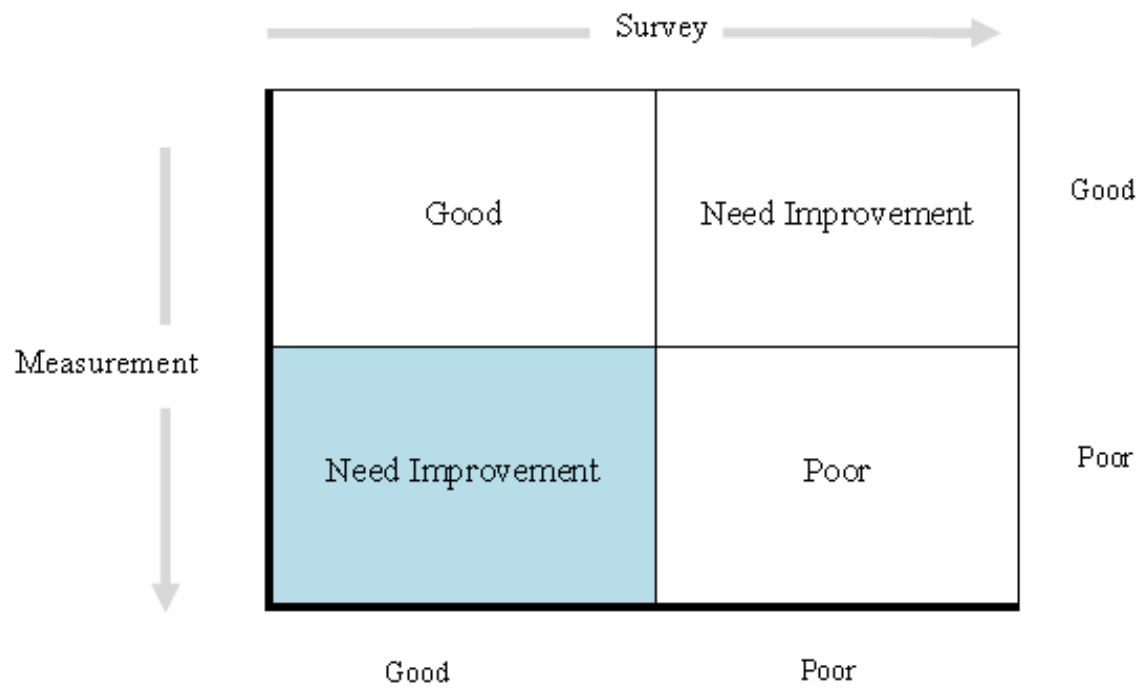

Figure 10. Matrix for the IEQ analysis at UKM architecture studio

According to this matrix shown in figure 11, the overall result showed that the IEQ for UKM architecture studio needs improvement since the temperature measurement and lighting measurement of internal studio environment are not up to the standard (poor). In addition, the result of the questionnaire survey for the existing scenario showed that at least $50 \%$ of the students were satisfied with the temperature comfort and humidity (good) and $70 \%$ of them were satisfied with the brightness in the UKM third year architecture studio (good). This matrix, therefore, concludes this finding.

Interestingly, the students were satisfied with the temperature setting for the internal studio, when the measurement itself showed contradicting ideas (with temperature recorded above $26{ }^{\circ} \mathrm{C}$ ). This could be due to the fact that different students might have different needs in terms of temperature setting. Even though the studio is fully air conditioned, the informal observation carried out during the survey found that a few sets of table fans were located near the student's workstation. Hence, this suggests that the use of fans is sometimes needed to achieve the students' expected comfort level. This somehow justifies why students have admitted that they could stay in the studio, even though the temperature measurements suggest otherwise. The temperature indicated was considered "hot" (with $26{ }^{\circ} \mathrm{C}$ and above) but the students took it as normal. This is actually acceptable for a short-term period. However, it can cause negative effects leading to sick building syndrome if the situation persists.

\section{Conclusions}

IEQ plays an important role in ensuring the studio has a learning environment that is conducive for architecture students. The findings show that the temperature and lighting setting of UKM third year architecture studio are not within the range of MS 1525:2007. However, according to the questionnaires, the students perceived it as normal (good) and this did not hinder them to stay for a long time inside the studio. The questionnaire results found that most of the architecture student agreed that the temperature comfort, humidity, day lighting, glare and brightness are most important for internal studio environment. The matrix of IEQ for the UKM third year 
architecture studio indicates that this particular studio falls under "Need Improvement". Action should be taken to improve the studio's IEQ especially on the temperature setting and the luminance level. Although the students perceived the existing temperature and lighting as normal and it did not hinder them to stay long inside their studio, this situation should only be appropriate for a short term learning environment. On the contrary, the situation might give negative health effect to the students in the long run. This finding can be used by lecturers or administrators to take appropriate measures to streamline the efforts towards providing a more conducive learning environment for the architecture studio.

\section{Acknowledgements}

This work was supported by Research Grant PTS-2012-011, OUP-2012-126 and the Centre for Engineering Education Research, Faculty of Engineering and Built Environment, Universiti Kebangsaan Malaysia, Bangi, Selangor, Malaysia.

\section{References}

Benya, J. R. (2001). Lighting for School. National Clearinghouse for Educational Facilities.

Bluyssen, P. (2009). The indoor environment handbook: How to make buildings healthy and comfortable. London : Earthscan.

Canter, D. V. (1976). Environmental Interaction Psychological Approaches to Our Physical Surroundings. New York: International University Press.

Che Ahmad, C. N., Osman, K., \& Halim, L. (2010). Hubungan Ramalan Persekitaran Pembelajaran Makmal Sains dengan Tahap Kepuasan Pelajar. Jurnal Pendidikan Malaysia, 35(2).

Dascalaki, G. E., Gaglia, G. A., Balaras, A. C., \& Lagoudi, A. (2008). Indoor Environmental Quality in Hellenic Hospital Operating Rooms. Elsevier.

Edwards, L., \& Torcellini, P. (2002). A Literature Review of the Effect of Natural Light on Building Occupants. National Renewable Energy Laboratory: Midwest Research Institute, Battelle, Bechtel. http://dx.doi.org/10.2172/15000841

Fang, L., Clausen, G., \& Fanger, P. O. (1998). Impact of Temperature and Humidity on Perception of Indoor Air Quality During Immediate and Longer Whole-Body Exposures. Indoor Air, 8(4), 276-284. http://dx.doi.org/10.1111/j.1600-0668.1998.00008.x

Fisk, W. J. (2000). Health and Productivity Gains from Better Indoor Environments and Their Implications for the U.S. Department of Energy. In Proceedings of E-Vision 2000 Conference. Washington, DC: Indoor Environment Department.

Fraser, B. J., Anderson, G. J., \& Walberg, H. J. (1982). Assessment on learning environment: manual for Learning Environment Inventory (LEI) and My Class Inventory (MCI) (3rd ed.). Perth Australia: Western Australian Institute of Technology.

Kamaruzzaman, S. N., \& Sabrani, N.A. (2011). The Effect of Indoor Air Quality (IAQ) Towards Occupants' Psychological Performance in Office Buildings. Journal Design + Built, 4.

Liberman, J. (1994). Light Medicine of the Future. New Mexico: Bear \& Company Publishing.

Mahbob, N. S., Kamaruzzaman, S. N., Salleh, N., \& Sulaiman, R. (2011). A Correlation Studies of Indoor Environmental Quality (IEQ) Towards Productive Workplace. 2nd International Conference on Environmental Science and Technology IPCBEE vol.6 (2011), IACSIT Press, Singapore.

Malaysian Standard MS1525. (2007). Code of Practice on Energy Efficiency and Use of Renewable Energy for Non-Residential Buildings. Department of Standards, Malaysia.

Mayron, L. W., Ott, J., Nations, R., \& Mayron, E. L. (1974). Light, radiation, and academic behaviour. Academic Therapy, 10(1), 33-47.

Osman, M. Z., Che-Ani, A. I., Tawil, N. M., Abdullah, N. A. G., Tahir, M. M., \& Surat, M. (2009). Keberkesanan Teori Pembelajaran Berasaskan Studio (PBS): Kajian Perbandingan Program Seni Bina Di Universiti Iowa Dan Universiti Kebangsaan Malaysia (UKM). Seminar Pendidikan Kejuruteraan dan Alam Bina (PeKA '09). Kongres Pengajaran dan Pembelajaran UKM 2009.

Ott Biolight Systems, Inc. (1997). Ergo Biolight Report. California: Ott Biolight Systems, Inc. 
Peccollo, M. (1962). The effect of thermal environment on learning. Unpublished doctoral dissertation, Iowa State University.

Plymton, P., Conway, S., \& Epstein, K. (2000). Daylighting in School: Improving Student Performance and Health at a Price School Can Afford. American Solar Energy Society Conference Madison, Wisconsin.

Prakash, P. (2005). Effect of Indoor Environmental Quality on Occupant's Perception of Performance: a Comparative Study. Master of Interior Design University of Florida.

Rivera, T. C., \& Ganaden, M. F. (2001). Classroom Psychosocial Environment. International Online Journal of Science and Mathematics Education, 1. Retrieved from http://www.upd.edu.ph/ ismed/online/articles/psycho/lit.htm

Seppänen, O., Fisk, W. J., \& Lei, Q. H. (2006). Effect of temperature on task performance in office environment. Lawrence Berkeley National Laboratory.

Wyon, D. P. (1991). The Ergonomics of Healthy Buildings: Overcoming Barriers to Productivity. In IAQ '91: Post Conference Proceedings. American Society of Heating, Refrigerating, and Air-Conditioning Engineers, Inc. Atlanta, pp. 43-46.

Zainol, M. Z. (2008). Efficient lighting based on energy efficiency and conservation guideline for Malaysian Industries. Universiti Teknologi Malaysia. Malaysia. 